Discussion Paper No. 11-041

\title{
Growth and Welfare Maximization in Models of Public Finance and Endogenous Growth
}

Florian Misch, Norman Gemmell, and Richard Kneller

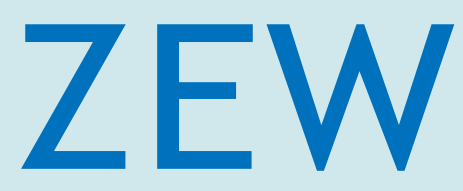

Zentrum für Europäische Wirtschaftsforschung $\mathrm{GmbH}$ Centre for European Economic Research 
Discussion Paper No. 11-041

\title{
Growth and Welfare Maximization in Models of Public Finance and Endogenous Growth
}

\author{
Florian Misch, Norman Gemmell, \\ and Richard Kneller
}

Download this ZEW Discussion Paper from our ftp server:

http://ftp.zew.de/pub/zew-docs/dp/dp11041.pdf

A previous version of this paper was released 2008 as a CREDIT Research Paper.

Die Discussion Papers dienen einer möglichst schnellen Verbreitung von neueren Forschungsarbeiten des ZEW. Die Beiträge liegen in alleiniger Verantwortung der Autoren und stellen nicht notwendigerweise die Meinung des ZEW dar.

Discussion Papers are intended to make results of ZEW research promptly available to other economists in order to encourage discussion and suggestions for revisions. The authors are solely responsible for the contents which do not necessarily represent the opinion of the ZEW. 


\section{Non-technical summary}

The comparison between growth-maximizing and welfare-maximizing fiscal policy over the long run is a central issue in models of public finance and endogenous growth. It is also important from a policymaking perspective: although the maximization of welfare is typically characterized as the primary objective of benevolent governments, imperfect knowledge about the preferences of households make it difficult to pursue a first-best strategy to achieve this. An obvious second-best strategy, because changes in income are easier to measure than welfare, is a policy of growth maximization. As a further complication, policy makers often perceive a distinction between the provision of social public services necessary to meet objectives related to social welfare and those expenditures necessary to achieve higher growth rates. Discussions of this nature feature frequently in policy debates.

This paper uses models of public finance and growth to evaluate the extent of the trade-off between growth and welfare maximization in the absence of redistributive issues, and therefore the policy conclusions with respect to the optimal tax rate and the optimal level of public spending that can be drawn, from two perspectives. The first compares the welfare-maximizing and growth-maximizing tax rates found under different assumptions in models of public finance and growth. In so doing we synthesize as well as extend the theoretical literature. A key outcome of this exercise is to highlight the range of conclusions that can be drawn from this class of theoretical models. The growth-maximizing tax rate can be the same as, higher, or lower than the welfare-maximizing equivalent, as a result of small changes in model assumptions about the nature of the effects of fiscal policy and the technology of private production.

The second perspective on the question of the trade-off between growth and welfare maximization considers the extent to which growth and welfare maximization yield distinct outcomes in terms of the growth rates and welfare levels along the balanced growth path. This is a question that is often ignored in the literature, even though ultimately, differences in outcomes represent the main trade-off of interest arising from growth versus welfare maximization objectives. The results from this exercise are striking and serve to modify the policy conclusions that might be drawn from the first part of the paper. Even when the differences between the tax rate necessary to maximize growth compared to the tax rate under welfare maximization are relatively large, we find that this translates into differences in growth rates that are relatively small, and in some cases, they also translate into relatively small differences in welfare levels.

We establish that this holds for a large array of possible parameter combinations and therefore appears to be robust. Particularly in models with public services, this suggests that growth maximization may be a suitable second-best strategy for benevolent governments. It occurs in part because the growth rate is a central determinant of welfare, but also because policy is relatively ineffective around the welfare and growth maxima. Hence, though previous models in the literature predict differences between welfare and growth maximization in a number of settings, we quantify these differences in our extended framework and show that differences in outcomes may be small. One inference is that in practice differences between growth and welfare maximization may not be a major concern such that some of the results in the existing literature overemphasize this dichotomy. 


\section{Das Wichtigste in Kürze}

Der Vergleich von langfristig wachstumsmaximierender und wohlfahrtsmaximierender Fiskalpolitik ist ein zentraler Gegenstand von endogenen Wachstumsmodellen, in denen Fiskalpolitik die langfristige Wachstumsrate der Volkswirtschaft beeinflusst. Dieser Vergleich ist ebenfalls wichtig aus einer wirtschaftspolitischen Perspektive: Obwohl die Maximierung von Wohlfahrt normalerweise das Ziel wohlwollender Regierungen ist, kann unvollständige Information hinsichtlich der Präferenzen der Haushalte die Verfolgung einer erstbesten Strategie deutlich erschweren. Die offensichtlich zweitbeste Strategie besteht darin, Wachstum zu maximieren, da Outputänderungen leichter zu messen sind und Wachstum eine zentrale Determinante von Wohlfahrt ist. Allerdings neigen politische Akteure dazu, einen Gegensatz zwischen der Bereitstellung von sozialen öffentlichen Dienstleistungen zur Erhöhung der Wohlfahrt und von produktiven öffentlichen Dienstleistungen zur Erhöhung von Wirtschaftswachstum zu sehen. Dieser wahrgenommene Gegensatz wird entsprechend oft öffentlich debattiert.

Diese Studie benutzt endogene Wachstumsmodelle mit öffentlichen Finanzen, um die Zielkonflikte zwischen der Maximierung von Wachstum und Wohlfahrt aus zwei Perspektiven zu evaluieren, wobei die Verteilung von Einkommen allerdings ignoriert wird. In der ersten Perspektive wird der wohlfahrts- und wachstumsmaximierende Steuersatz unter unterschiedlichen Modellannahmen verglichen. Ein zentrales Ergebnis dieser Analyse besteht darin, dass mögliche optimale Steuersätze eine erhebliche Bandbreite haben können. Der wachstumsmaximierende Steuersatz kann - abhängig von den Modellannahmen hinsichtlich der Produktionstechnologie und der Effekte öffentlicher Ausgaben - dem wohlfahrtsmaximierenden Steuersatz entsprechen, aber auch darüber oder darunter liegen.

In der zweiten Perspektive wird untersucht, ob Wachstums- und Wohlfahrtsmaximierung zu unterschiedlichen Outcomes hinsichtlich der Höhe des Wachstums- und des Wohlfahrtniveaus führen. Unterschiede bei den Outcomes werden nur selten in der Literatur analysiert, obwohl diese letztenendlich das Ausmaß von Zielkonflikten bestimmen. Die Ergebnisse dieser Analyse modifizieren die Schlussfolgerungen, die im ersten Teil des Papiers gezogen werden: Während große Unterschiede zwischen wachstums- und wohlfahrtsmaximierenden Steuersätzen bestehen können, sind die Unterschiede zwischen den Wachstumsraten und in einigen Fällen zwischen den Stufen des erreichten Wohlfahrtniveaus unter beiden Politikzielen gering.

Wir zeigen, dass diese Schlussfolgerungen für eine große Anzahl von verschiedenen Modellparametern robust sind. Dies impliziert, dass Wachstumsmaximierung eine mögliche zweitbeste Strategie für wohlwollende Regierungen ist. Dies kann dadurch erklärt werden, dass Fiskalpolitik zwischen den Wachstums- und Wohlfahrtsmaxima relativ ineffektiv ist. Diese Schlussfolgerungen relativieren ebenfalls einige Ergebnisse von vorherigen Studien, die zeigen, dass Unterschiede zwischen Wachstums- und Wohlfahrtsmaximierung bestehen. Eine Implikation dieser Ergebnisse besteht darin, dass in der Praxis die Unterschiede zwischen Wachstums- und Wohlfahrtsmaximierung nicht zu sehr betont werden sollten. 


\title{
Growth and Welfare Maximization in Models of Public Finance and Endogenous Growth*
}

\author{
Florian Misch ${ }^{a, \dagger}$, Norman Gemmell ${ }^{b, c, \ddagger}$ and Richard Kneller ${ }^{b, \S}$ \\ ${ }^{a}$ Centre for European Economic Research, 68161 Mannheim, Germany \\ ${ }^{b}$ School of Economics, University of Nottingham, Nottingham NG7 2RD, UK \\ ${ }^{c_{\text {The Treasury, }}}$ PO Box 3724, Wellington 6140 , New Zealand
}

June 8, 2011

\begin{abstract}
This paper evaluates the trade-off between growth and welfare maximization from two perspectives. Firstly, it synthesizes and extends endogenous growth models with public finance to compare growth and welfare maximizing tax rates. Secondly, it examines the distinct model outcomes in terms of their growth rates and welfare levels. This comparison highlights the range of trade-offs: the growth maximizing tax rate can be above, below, or equal to the welfare maximizing equivalent. We find however that even relatively large differences in growth and welfare maximizing tax rates translate into relatively small differences in growth rates, and, in some cases, welfare levels.
\end{abstract}

JEL code: E62, H21, H50, O40

Keywords: Economic Growth, Productive Public Spending, Optimal Fiscal Policy

\footnotetext{
*A previous version of this paper was released 2008 as a CREDIT Research Paper.

${ }^{\dagger}$ Corresponding author. E-mail address: misch@zew.de / Telephone: +49 (0)621 1235394 / Fax: +49 (0)621 1235-223

${ }^{\ddagger}$ E-mail address: norman.gemmell@nottingham.ac.uk

${ }^{\S}$ E-mail address: richard.kneller@nottingham.ac.uk
} 


\section{Introduction}

The comparison between growth-maximizing and welfare-maximizing fiscal policy over the long run is a central issue in models of public finance and endogenous growth. It is also important from a policy-making perspective: although the maximization of welfare is typically characterized as the primary objective of benevolent governments, imperfect knowledge about the preferences of households make it difficult to pursue a first-best strategy to achieve this. An obvious second-best strategy, because changes in income are easier to measure than welfare, is a policy of growth maximization. As a further complication, policy makers often perceive a distinction between the provision of social public services necessary to meet objectives related to social welfare and those expenditures necessary to achieve higher growth rates. Discussions of this nature feature frequently in policy debates, such as with respect to appropriate fiscal policies for developing countries. ${ }^{1}$

This paper uses models of public finance and growth to evaluate the extent of the trade-off between growth and welfare maximization, and therefore the policy conclusions with respect to the optimal tax rate and the optimal level of public spending that can be drawn, from these two perspectives. The first compares the welfare-maximizing and growth-maximizing tax rates found under different assumptions in models of public finance and growth. In so doing we synthesize as well as extend the theoretical literature. A key outcome of this exercise is to highlight the range of conclusions that can be drawn from this class of theoretical models. The growth-maximizing tax rate can be the same as, higher, or lower than the welfare-maximizing equivalent, as a result of small changes in model assumptions about the nature of the effects of fiscal policy and the technology of private production. As a consequence, well known results in the existing literature are not robust to small changes in their underlying assumptions. These include the Barro

\footnotetext{
${ }^{1}$ See for example IMF and World Bank (2007). For instance, the Tanzanian National Strategy for Growth and Reduction of Poverty contains a cluster for 'Growth and the reduction of income poverty' and another cluster on 'Improved quality of life and social well-being' that both list the provision of various public services and various types of public investment. The division into two clusters reflects the perception that there are trade-offs.
} 
(1990) model with a flow of productive public services where the growthand welfare-maximizing tax rates coincide, and the Futagami et al. (1993) model with productive public capital, where the growth-maximizing tax rate exceeds the welfare-maximizing tax rate. $^{2}$

We examine the trade-offs between growth and welfare maximization using two alternative endogenous growth models. One is a generalization of the Barro (1990) model (i.e. the government provides public services) while the other generalizes the Futagami et al. (1993) model (i.e. the government accumulates public capital). We make two extensions to these frameworks. In the first extension we allow for the possibility that public services or public capital entail mixed effects; the same public service/capital may simultaneously be productive as well as utility-enhancing. A given type of health or education spending, for example, may often simultaneously enhance private sector output or productivity and target social welfare objectives. In developing countries where the government typically provides more rudimentary public services, arguably there are few public services that entail purely productive or purely utility-enhancing effects. ${ }^{3}$

In the second extension, we allow for greater complementarity between productive public services and private capital than in the Cobb-Douglas case (the elasticity of substitution is assumed to be less than one). Public services provided by the government fundamentally differ from private inputs, such that it may be very costly for firms to substitute for them. For example, poor quality road surfaces may require firms to purchase special, more expensive, vehicles for the transportation of goods.

We consider various combinations of these assumptions. While the presence of mixed effects increases the welfare-maximizing tax rate relative to the

\footnotetext{
${ }^{2}$ Throughout the chapter, the term 'Barro Model' refers to the main model developed in Barro (1990), and the term 'Futagami Model' refers to the model developed in Futagami et al. (1993). The term 'public services' denotes public services derived from the flow of public spending, whereas the term 'public capital' is equivalent to public services derived from the stock of public capital.

${ }^{3}$ For example, public transportation infrastructure may not only be productive because it facilitates access to hospitals and primary health facilities but may also be productive because it ensures that the labour force remains fit for work. Agénor and Neanidis (2006) provide a survey of empirical evidence on the impact of health on growth and the impact of infrastructure on health outcomes.
} 
growth-maximizing equivalent, complementarity tends to have the opposite effects. This implies that combining both additions lead to potentially more interesting results because they serve to increase the ambiguity of the conclusion regarding the relationship between growth- and welfare-maximizing tax rates. Since closed-form solutions cannot be obtained in most cases, it is shown numerically that with public capital that entails mixed effects, the Futagami et al. (1993) results no longer holds, and that with a higher degree of complementarity the same is true for the Barro (1990) result that growthand welfare-maximizing fiscal policies are identical. It is therefore the derivation of optimal fiscal policy under growth and welfare maximization in these types of settings with complementarity and mixed public spending effects which is our first contribution.

The second perspective on the question of the trade-off between growth and welfare maximization considers the extent to which growth and welfare maximization yield distinct outcomes in terms of the growth rates and welfare levels along the balanced growth path. This is a question that is often ignored in the literature, even though ultimately, differences in outcomes represent the main trade-off of interest arising from growth versus welfare maximization objectives. This analysis is provided through numerical simulations of policies and outcomes under growth and welfare maximization for a wide range of parameter sets that nest different degrees of complementarity between public services/capital and private capital.

The results from this exercise are striking and serve to modify the policy conclusions that might be drawn from the first part of the paper. Even when the differences between the tax rate necessary to maximize growth compared to welfare maximization are relatively large, we find that this translates into differences in growth rates that are relatively small. For models with public services, they also translate into relatively small differences in welfare levels. This conclusion is also likely to hold for models with public capital. That is, even where there is uncertainty about how a particular form of public service or capital affects the production function or the utility function, in practice growth maximization yields growth outcomes (and in many cases, welfare outcomes) that are very close to those found under welfare maximization. 
We establish that this holds for a large array of possible parameter combinations and therefore appears to be robust. Particularly in models with public services, this suggests that growth maximization may be a suitable second-best strategy for benevolent governments. It occurs in part because the growth rate is a central determinant of welfare, but also because policy is relatively ineffective around the welfare and growth maxima. Large differences in fiscal policy suggested by growth and welfare optimization translate into small growth and welfare differences. This result occurs in a class of models that ensure long-run impacts of fiscal policy, and which has typically formed the reference point for much theoretical discussion and empirical testing of the impacts of fiscal policy and long-run growth. ${ }^{4}$

Hence, though previous models in the literature predict differences between welfare and growth maximization in a number of settings, we quantify these differences in our extended framework and show that differences in outcomes may be small. One inference is that in practice differences between growth and welfare maximization may not be a major concern such that some of the results in the existing literature overemphasize this dichotomy.

The remainder of the paper is organized as follows. Section 2 develops the models and derives the equilibrium in the market economy. Section 3 compares the growth- and welfare-maximizing tax rates, while Section 4 uses numerical examples to compare growth rates and welfare levels along the balanced growth path (under both growth and welfare maximization). Finally, Section 5 summarizes the results and discusses some policy implications.

\section{Theoretical Framework}

The public finance growth framework we adopt is based on Barro (1990) and Futagami et al. (1993). We assume a large number of identical and infinitely lived households normalized to one, and zero population growth. The household produces a single composite good which can be used for consumption or physical capital accumulation. We develop two distinct models (1 and 2) in order to obtain more general conclusions about the extent and nature of the

\footnotetext{
${ }^{4}$ See Turnovsky (2004) for a more extenive discussion.
} 
trade-offs between growth and welfare maximization that can arise in this class of models.

In Model 1, the government provides public services which are derived from the flow of public spending. To incorporate the notion of complementarity between private and public services, the production function is a generalized version of that found in Barro (1990). Output is produced using private capital $(k)$ and a non-rival and non-excludable productive public service $(g)$ based on CES technology:

$$
y=\left(\theta k^{v}+\alpha g^{v}\right)^{\frac{1}{v}}
$$

where $\theta=1-\alpha$. The parameter $v$ determines the elasticity of substitution given by:

$$
s=\frac{1}{1-v}
$$

The government levies a proportional tax on output at rate $\tau$, to provide public services. Hence:

$$
g=\tau y
$$

The instantaneous utility function is

$$
u(c, g)=\frac{\left(g^{\beta} c^{1-\beta}\right)^{1-\sigma}}{1-\sigma}
$$

where, unlike Barro (1990), productive public spending, $g$, also directly enters the utility function. ${ }^{5}$ The market equilibrium in Model 1 can be characterized as follows. The representative household chooses the consumption path to maximize lifetime utility $U$ given by

$$
U=\int_{0}^{\infty} u(c(t), g(t)) e^{-\rho t} d t
$$

subject to the production function and the household's resource constraint taking $\tau, g$ and $k_{0}$ as given. ${ }^{6}$

\footnotetext{
${ }^{5}$ In an extension to his main model, Barro (1990) allows for a different non-productive public spending category, $h$, to affect household utility.

${ }^{6}$ In addition, the transversality condition has to be fulfilled. This is the case irrespective of the policy choice if $\sigma>1$ which we assume throughout the paper. The time subscript is omitted whenever possible. A dot over the variable denotes its derivative with respect to time.
} 
Using the first-order conditions and noting that there are no transitional dynamics in this model, so that $c, k$ and $y$ all grow at the same constant rate $\gamma$, the growth rate can be written as

$$
\gamma=\frac{\dot{c}}{c}=\frac{1}{\sigma}\left((1-\tau) y_{k}-\rho\right)
$$

Since $\beta$ does not enter the latter expression, it can be noted that in the market economy the presence of mixed effects of public services does not affect the growth rate.

In Model 2, the government accumulates public capital. Similar to Model 1, we assume a generalized version of the production function in Futagami et al. (1993), who assume that output is a function of public capital $\left(k_{G}\right)$, to allow for public-private complementarity, such that (1) is rewritten as:

$$
y=\left(\theta k^{v}+\alpha k_{G}^{v}\right)^{\frac{1}{v}}
$$

Similarly, (3) and (4) become:

$$
\dot{k}_{G}=\tau y
$$

and

$$
u\left(c, k_{G}\right)=\frac{\left(k_{G}^{\beta} c^{1-\beta}\right)^{1-\sigma}}{1-\sigma}
$$

In this case, the market equilibrium can be characterized as follows. The representative household now maximizes lifetime utility given by

$$
U=\int_{0}^{\infty} u\left(c(t), k_{G}(t)\right) e^{-\rho t} d t
$$

subject to (7) and the household's resource constraint taking $\tau, k_{G}>0$ and $k_{0}>0$ as given.

Using the first-order conditions, it can be shown that along the balanced growth path, the growth rate has to satisfy

$$
\gamma=\frac{\dot{c}}{c}=\frac{1}{\sigma}\left((1-\tau) y_{k}-\rho\right)
$$

but which is not a closed-form solution of $\gamma$ because now $y_{k}$ is a function of $\gamma$. Along the lines of Futagami et al. (1993), it can be shown that the 
equilibrium of the model is saddlepoint stable within the relevant parameter ranges, and that the balanced growth path is unique. As above, $\beta$ does not enter (11).

Different values of the exogenous parameters in Models 1 and 2 can generate different implications about the extent of the utility-enhancing effects of public spending and about the extent of complementarity between public and private inputs to production. Public spending simultaneously affects private production and utility if $\alpha>0$ and $\beta>0$. If $v<0$, the elasticity of substitution is smaller than in the case of Cobb-Douglas technology, and private capital and public inputs are complements. In contrast, with $\beta=0$, public spending is solely productive, and with $v=0$, output is produced using Cobb-Douglas technology such that Model 1 is identical to Barro (1990), and Model 2 is identical to Futagami et al. (1993). Obviously, constraining either $\beta$ or $v$ to zero, it is also possible to generate versions of Models 1 and 2 that either incorporate mixed effects of public spending or complementarity, but not both.

\section{Fiscal Policy under Growth and Welfare Maximization}

\subsection{Model 1}

This sub-section derives the growth-maximizing tax rate, $\tau^{*}$, and the welfaremaximizing tax rate, $\tau^{* *}$, in different versions of Model 1 that differ with respect to the assumptions of the effects of public services and the degree of complementarity. ${ }^{7}$ The growth-maximizing tax rate maximizes the longrun growth rate of the economy, whereas the welfare-maximizing tax rate maximizes lifetime utility of the representative household and is therefore Ramsey-optimal. We assume that the tax rate is constant over time.

For illustrative purposes, we first derive the growth- and welfare-maximizing tax rate under the assumption that $\beta=0$ and $v=0$ which corresponds to the Barro (1990) model and which implies that public spending is solely

\footnotetext{
${ }^{7}$ We consider the optimal fiscal policies in the centralized economy in the appendix.
} 
productive. Later, we successively add the assumptions of mixed effects of public spending and complementarity. Maximizing the growth rate in the Barro Model yields its familiar growth-maximizing tax rate, $\tau^{*}$ :

$$
\tau^{*}=\alpha
$$

In the Barro Model, maximizing output net of taxation at every point of time yields the same tax rate as maximizing the growth rate. Since lifetime utility is a function of current consumption which depends on current output and future consumption which in turn depends on long-run growth, there are therefore no trade-offs between growth maximization and welfare maximization in the Barro Model. The growth- and welfare-maximizing tax rates $\left(\tau^{*}\right.$ and $\tau^{* *}$, respectively) therefore coincide:

$$
\tau^{*}=\tau^{* *}=\alpha
$$

We now assume that public spending has mixed effects (i.e. $\beta>0$ ), but that the technology of production is Cobb-Douglas technology $(v=0)$. Given that the production technology has not changed, the growth-maximizing tax rate, $\tau^{*}$, corresponds to the previous case where $\beta=0$ because the growth rate (6) is not affected by the choice of $\beta$. Hence $\tau^{*}=\alpha$.

The welfare-maximizing tax rate can be calculated as follows. Since there are no transitional dynamics in Model 1, by taking the integral of (5), lifetime utility can be expressed as (ignoring the constants):

$$
U=\frac{1}{1-\sigma}\left[\frac{\left(\left(\frac{g}{k}\right)^{\beta} x^{1-\beta}\right)^{1-\sigma}}{\rho-(1-\sigma) \gamma}\right]
$$

where $x=c / k$. Maximizing the latter expression yields the welfare-maximizing tax rate $\tau^{* *}$ when $\beta>0$. Since closed-form solutions cannot be obtained, we compare the growth- and welfare-maximizing tax rate numerically. Specifically, Figure 1 plots the growth- and welfare-maximizing tax rates as functions of $\beta$ when $v=0$. It shows that the welfare-maximizing tax rate exceeds the growth-maximizing tax rate when output is produced using CobbDouglas technology and when public services are assumed to have mixed 
effects. That is, due to the simultaneous utility-enhancing effect of public services, higher spending levels are more desirable from a welfare perspective than from a growth perspective. Figure 1 demonstrates that depending on the value of $\beta$, the difference may be sizeable suggesting potentially significant trade-offs for fiscal policy between growth and welfare maximization. We refer to this source of trade-off as the 'utility-enhancement effect'.

Next, we assume that public spending has only productive effects $(\beta=0)$, but that private and public inputs are complements. Specifically, to simplify the exposition, we assume that the elasticity of substitution is $\frac{1}{2}$ (implying $v=-1$, which is halfway between the Cobb-Douglas and Leontief technologies. This yields a larger (smaller) degree of complementarity between the inputs to private production than Cobb-Douglas (Leontief) technology. The growth-maximizing tax rate with $v=-1$ and $\beta=0$ is

$$
\tau^{*}=\frac{1}{2}\left(\sqrt{\alpha^{2}+8 \alpha}-\alpha\right)
$$

While the welfare-maximizing tax rate can be calculated by analogy to the previous case, there are again no closed-form solutions. Figure 2 compares the growth- and welfare-maximizing growth rate numerically. It shows that even when $\beta$ is constrained to zero and when $v=-1$, the welfare-maximizing tax rate no longer matches the growth-maximizing tax rate, with the former below the latter. As Barro (1990) predicts, the elasticity of substitution affects the relationship between the welfare and growth-maximizing tax rates. The reason is that maximizing output net of taxation and hence maximizing current and future consumption are no longer identical to maximizing the growth rate. We refer to this as the 'complementarity effect'.

Finally, we assume that public spending has mixed effects $(\beta>0)$ and that private and public inputs to production are complements (i.e. $v=$ -1 as in the previous case). The growth-maximizing tax rate in this case corresponds to (15) and is therefore not affected by $\beta$. As there are no closed-form solutions for the welfare-maximizing tax rate, we again compare the growth- and welfare-maximizing tax rate numerically in Figure 2. It shows that when we allow for mixed public services and for complementarity (an elasticity of substitution of less than one), we find that the welfare- 
maximizing tax rate increases with $\beta$, and its position with regard to the growth-maximizing tax rate is ambiguous. A smaller elasticity of substitution lowers the welfare-maximizing tax rate (complementarity effect), whereas it increases with $\beta$ (utility-enhancement effect). For low values of $\beta$, the welfaremaximizing tax rate is below the growth-maximizing rate, with the reverse true for high values of $\beta$.

For illustrative purposes, it is useful to also consider values of $v$ that lie outside the range of -1 and 0 even though we regard them as less realistic and hence less relevant. If $v=1, y=\theta k+\alpha g$ implying that private and public inputs are perfect substitutes. In this case, the growth-maximizing tax rate is 0 because providing public services imposes a cost in terms of distortions from income taxation on the economy. With full substitutability, it would be inefficient to bear these costs under growth maximization which reflects the fact that there is no rationale for government intervention as public services are not sufficiently different from private inputs. In contrast, there is still potentially a rationale to set the tax rate above zero when public spending has mixed effects under welfare maximization. ${ }^{8}$

For $v=-\infty$, the technology of production becomes Leontief so that public services and private capital are complete complements: $y=\min (\theta k, \alpha g)$. In this setting, there is no long-run output growth irrespective of the level of taxation. The reason is related to the fact that whereas public services are derived from the flow of public expenditure only, $k$ is a stock that is accumulated over time so that in the long run, $g$ - which essentially fully depreciates after each period - cannot exceed $k$. In other words, the share of $g$ in $y$ is necessarily constrained to be lower than one in contrast to the stock of capital which may exceed the level of output. In turn, $g \leq k$ implies that private investment has zero marginal returns and does not occur so that there is neither capital accumulation nor growth over the long-run. We therefore do not discuss this case further.

\footnotetext{
${ }^{8}$ Setting $v=1$ and $\beta=0.3$, the welfare-maximizing tax rate would be for instance 0.24 (when the remaining parameters set at the same values as in Figure 2).
} 
Figure 1: The tax rate as a function of $\beta$ in Model 1 with $v=0$

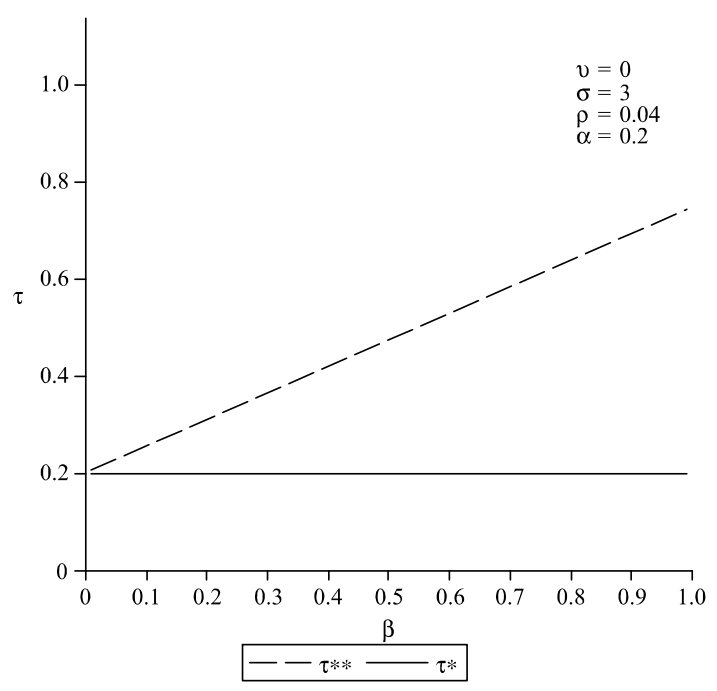

\section{$3.2 \quad$ Model 2}

Analogous to the previous sub-section, this sub-section derives the tax rate which maximizes growth along the balanced growth path, $\tau^{*}$, and the welfaremaximizing tax rate, $\tau^{* *}$, which maximizes lifetime utility in various versions of Model 2. The latter differ with respect to the assumptions about the effects of public capital (whether they are only growth-enhancing or mixed) and the elasticity of substitution (whether it is below one or equal to one). This allows us to show how these assumptions affect the trade-offs between growth and welfare maximization in Model 2 where the government's accumulation of public capital affects private production. ${ }^{9}$

Again, for illustrative purposes, we first derive the growth- and welfaremaximizing tax rate under the assumption that $\beta=0$ and that $v=0$ which corresponds to the Futagami et al. (1993) model and which implies that public spending is solely productive. Futagami et al. (1993) have shown that, in this setting, the growth-maximizing tax rate is

$$
\tau^{*}=\alpha
$$

\footnotetext{
${ }^{9}$ Note that while there are transitional dynamics in Model 2, we implicitly assume that the costs of changing the tax rate are prohibitively high so that the government is only able to set the tax rate once.
} 
Figure 2: The tax rate as a function of $\beta$ in Model 1 with $v=-1$

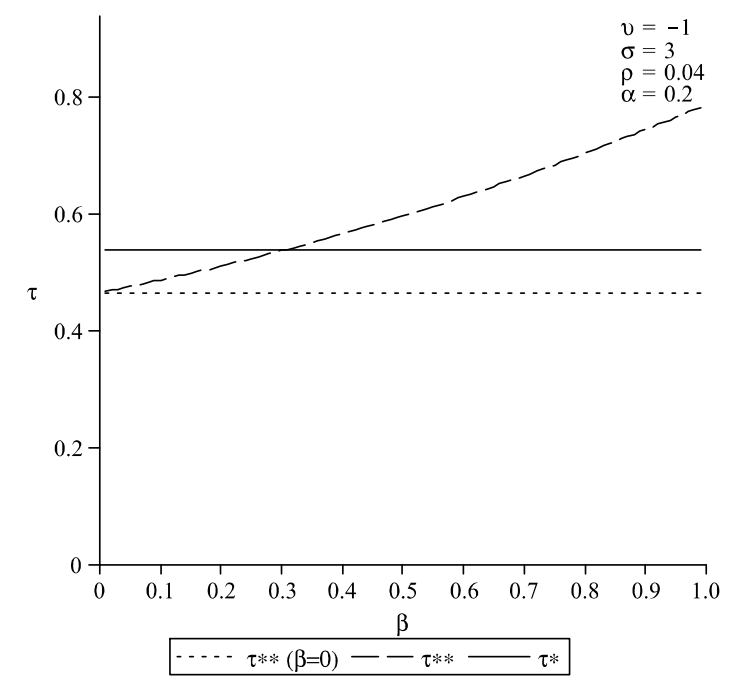

Under welfare maximization in the market economy, the government maximizes (5) subject to the resource constraint of the household and (8) while taking the first-order conditions of the households as given. Futagami et al. (1993) have shown that the growth-maximizing tax rate exceeds the welfaremaximizing rate. The reason is that when public services are derived from the stock of public capital, there are transitional dynamics and consumption is foregone in the process of accumulating public capital (Turnovsky, 1997), which has adverse consequences for welfare. This implies that maximizing the level of current output and maximizing the long-run growth rate are no longer identical. This effect is termed the 'capital accumulation effect' and arises because of transitional dynamics. Along the lines of Ghosh and Roy (2004), in the Appendix we derive the conditions that the welfare-maximizing tax rate has to satisfy. Given that there are no closed-form solutions available, Figure 3 compares the growth- and welfare-maximizing tax rate under the assumption that $\beta=0$ and $v=0$ and confirms the results of Futagami et al. (1993) that $\tau^{* *}<\tau^{*}$.

Now assume that public spending has mixed effects $(\beta>0)$, but that the technology of production is Cobb-Douglas $(v=0)$. Given that the production technology has not changed, the growth-maximizing tax rate, $\tau^{*}$, corre- 
sponds to (16). The welfare-maximizing tax rate can be calculated as shown in the Appendix, but no closed-form solutions exist. ${ }^{10}$ We therefore again use numerical examples to compare the growth- and welfare-maximizing tax rates in this case in Figure 3. As might be expected from this configuration of results when we consider the model with mixed public services, the impact of increasing $\beta$ on the relative position of the welfare-maximizing tax rate is ambiguous. The utility-enhancement effect and the capital accumulation effect oppose each other. For low values of $\beta$ the welfare-maximizing tax rate is below the growth-maximizing rate, whereas for high values of $\beta$ it lies above it, and there exists a particular value of $\beta$ when both tax rates are identical.

Next, we assume that public capital has only productive effects $(\beta=0)$, but that private and public inputs are complements, and as above, the elasticity of substitution is $\frac{1}{2}$. Figure 4 shows that even when $\beta=0$, compared to the case where there is no complementarity between private and public capital ( $v=0$ as in the Futagami Model), the effect of the change in the assumption with respect to the elasticity of substitution is to accentuate the difference between the growth- and welfare-maximizing tax rates. Here the capital accumulation and complementarity effects are reinforcing.

Finally, we consider the case where public spending has mixed effects $(\beta>0)$ and private and public inputs to production are complements $(v=$ $-1)$. Figure 4 compares the growth-maximizing and welfare-maximizing tax rates. The fact that public capital also affects utility results in the welfare-maximizing tax rate increasing with $\beta$ (as when $v=0$; see Figure 3), and its position with regard to the growth-maximizing tax rate is again ambiguous. The small elasticity of substitution (complementarity effect) and the capital accumulation effect lower the welfare-maximizing tax rate, whereas the utility-enhancement effect raises it, such that it crosses the growth-maximizing tax rate at some point.

For illustrative purposes, we again consider the case of full substitutability $(v=1)$ or nearly full substitutability and the case of Leontief technology

\footnotetext{
${ }^{10}$ As shown in the Appendix, the welfare-maximizing tax rate has to satisfy equations (A.1), (A.2) and (A.3).
} 
$(v=-\infty)$. In the former, there is again no rationale for public investment under growth maximization because it is more efficient to produce private output solely using private inputs. Under welfare maximization (and with $v$ set close to 1) and in contrast to Model 1, the optimal tax rate is likewise approximately zero in many cases even if public capital entails significant utility-enhancing effects ${ }^{11}$. Intuitively, this result arises because the negative effects of increasing the tax rate (i.e. consumption foregone in the process of accumulating public capital) exceed the positive effects (i.e. higher utilityenhancing public services and higher output over the long-run).

In the latter case $(v=-1)$, the growth rate is either 0 or $(1-\tau) \theta$ depending on whether $k$ is larger or smaller than $k_{G}$. In contrast to Model 1, a priori, it is unclear whether $k>k_{G}$ and $\gamma=0$ or not because $k_{G}$ is also accumulated over time. Growth is hence maximized with the tax rate that leads to $k_{G}$ being infinitesimally larger than $k$. However, given the discontinuous nature of the growth rate, the dynamic properties of the model are likely to differ. Whether there would be a stable growth equilibrium is therefore unclear; we do not pursue this rather special case further below.

Figure 3: The tax rate as a function of $\beta$ in Model 2 with $v=0$

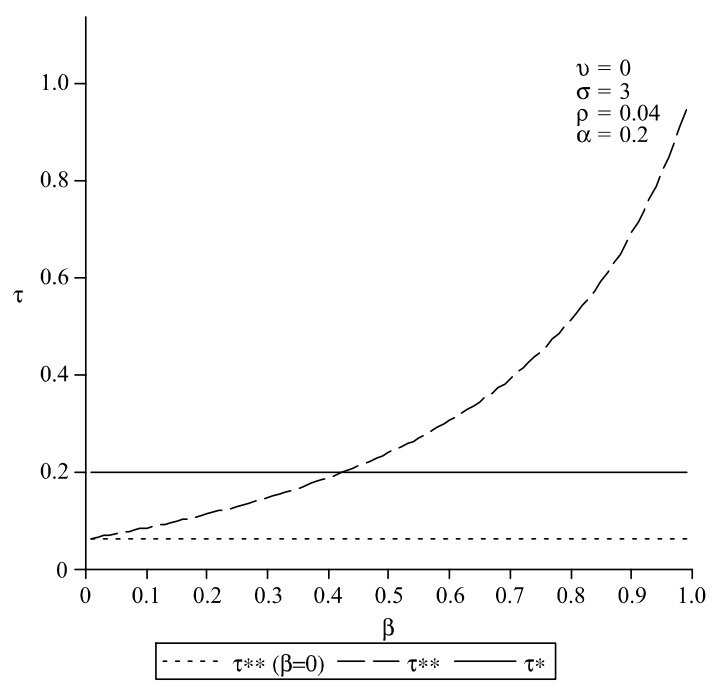

\footnotetext{
${ }^{11}$ For instance, with $v=0.97, \beta=0.5$, and with all the remaining parameters set as in Figure $4, \tau^{* *} \approx 0$.
} 
Figure 4: The tax rate as a function of $\beta$ in Model 2 with $v=-1$

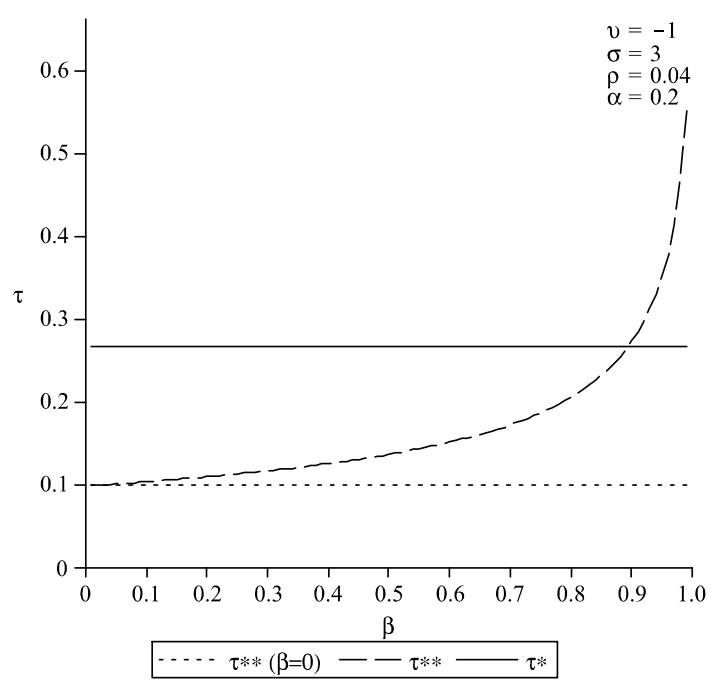

\subsection{Summary of the Results}

The previous sub-sections have shown how the trade-off between growth and welfare maximization is affected by assumptions with respect to the effects of public spending and the substitutability between private and public inputs to production in growth models where the government either provides public services derived from the flow of public spending or accumulates public capital. Table 1 provides an overview of the different assumptions made.

To summarize, it has been shown that small changes in the underlying assumptions of the Barro and Futagami Models can lead to fundamentally different conclusions from comparisons between the growth- and welfaremaximizing tax rates. Due to the lack of closed-form solutions in several versions of the model, this section presented numerical comparisons between growth and welfare maximization. Specifically, we plotted the growth- and welfare-maximizing tax rates as functions of $\beta$ under alternative assumptions in Models 1 and 2. This allows us to compare the growth- and welfaremaximizing tax rates across a wide range of parameter configurations, and provides an indication of the magnitude of potential differences.

Without knowledge of the way that public services or capital affect pro- 
duction or utility, governments can neither be sure about whether the welfaremaximizing tax rate is expected to be above, below or to be the same as the growth-maximizing tax rate, nor about the size of that difference. Several generalizations are possible however.

(1) The use of public capital, as in the Futagami Model, tends to yield outcomes in which the welfare-maximizing tax rate is below the growthmaximizing rate (capital accumulation effect).

(2) The use of 'mixed' public services or public capital - that affect both production and utility - raises the welfare-maximizing tax rate so that it may lie above the growth-maximizing rate (utility-enhancement effect).

(3) In models in which the elasticity of substitution between public services and private capital is less than one, the welfare-maximizing tax rate lies below the growth-maximizing rate (complementarity effect).

As a consequence it is possible to generate versions of the endogenous growth models that differ with respect to (a) how public spending affects private production, (b) whether they also affect utility, and (c) the elasticity of substitution between private and public inputs to private production, in which these differences in tax rates are magnified or become ambiguous. Table 1 summarizes the range of results from alternative assumptions in Models 1 and 2 .

In comparison with the previous literature, to our knowledge no previous papers compare the growth- and welfare-maximizing tax rates in models that include mixed effects and allow for complementarity. A few papers have developed similar models that either assume that public spending has mixed effects or that there is complementarity between public and private inputs, but comparisons between growth- and welfare-maximizing fiscal policies generally refer to the case of a centralized, rather than market, economy. Examples of comparisons between growth and welfare maximization in the former type of models include Balducci (2005), Agénor (2008a) and Agénor (2008b). ${ }^{12}$ Likewise, a few models consider CES technology within endogenous growth

\footnotetext{
${ }^{12}$ Comparing welfare maximizing and growth maximizing fiscal policies within a model in which public capital is productive and utility-reducing due to negative welfare effects of growth (pollution) is proposed for further research by Greiner and Kuhn (2005).
} 
models with public spending; see Devarajan et al. (1996), Baier and Glomm (2001) and Ott and Turnovsky (2006). However, as we demonstrate above, it is the combination of these features that leads to ambiguous, and therefore potentially more interesting, results with respect to the difference between growth and welfare maximization. As an exception, Chatterjee and Ghosh (2009) develop a model that includes both complementarity and mixed effect features, but they do not derive results for growth- versus welfare-maximizing fiscal policies. ${ }^{13}$

Our results also markedly contrast with the those of Barro (1990), Lau (1995), Greiner and Hanusch (1998) and Park and Philippopoulous (2002), who assume that growth-enhancing and utility-enhancing public services are distinct. In these models, the welfare-maximizing tax rate can be expected to be well above the growth-maximizing equivalent because the utlitityenhancing public services impose additional public spending requirements on the government under welfare maximization compared to the case of growth maximization where the effects of these public services are ignored by the government. ${ }^{14}$ These types of models may well exaggerate the difference between both tax rates in the light of the evidence that many public services have mixed effects, especially in developing countries.

\section{Growth Rates and Welfare Levels under Growth and Welfare Maximization}

In this section we turn to the comparison of the outcomes that result from the different versions of the public finance and growth models considered above. In particular we are interested in whether the ambiguous nature of

\footnotetext{
${ }^{13}$ The features of our model and the focus of our analysis imply that our results are not comparable to those obtained within the broader literature on optimal taxation which we define to include studies such as Chari et al. (1994) either. Apart from the fact that in these models long-run growth does typically not arise, the focus of their analysis is to determine the optimal structure of taxation, where typically, public spending requirements are exogenously given. In contrast, our focus is to determine the optimal level of public spending when public spending entails growth-enhancing and utility-enhancing effects.

${ }^{14}$ This holds as long as utility is positive in the absence of utility-enhancing public services.
} 
Table 1: Model summary

\begin{tabular}{lcccc}
\hline Model & $\beta$ & $v$ & $\begin{array}{c}\text { Relationship } \\
\text { between } \\
\tau^{*} \text { and } \tau^{* *}\end{array}$ & $\begin{array}{c}\text { Description } \\
\text { of } \\
\text { Assumptions }\end{array}$ \\
\hline Model 1 & $\beta=0$ & $v=0$ & $\tau^{*}=\tau^{* *}$ & Barro Model \\
Model 1 & $\beta>0$ & $v=0$ & $\tau^{*}<\tau^{* *}$ & mixed effects \\
Model 1 & $\beta=0$ & $v=-1$ & $\tau^{*}>\tau^{* *}$ & complementarity \\
Model 1 & $\beta>0$ & $v=-1$ & ambiguous & mixed effects\&complementarity \\
Model 2 & $\beta=0$ & $v=0$ & $\tau^{*}>\tau^{* *}$ & Futagami Model \\
Model 2 & $\beta>0$ & $v=0$ & ambiguous & mixed effects \\
Model 2 & $\beta=0$ & $v=-1$ & $\tau^{*}>\tau^{* *}$ & complementarity \\
Model 2 & $\beta>0$ & $v=-1$ & ambiguous & mixed effects\&complementarity \\
\hline
\end{tabular}

the differences in tax rates with welfare and growth maximization translate into large or small differences in outcomes. We perform this exercise by quantifying differences between the growth rates and welfare levels along the balanced growth path under growth and welfare maximization. The motivation is that while the extent of trade-offs between both government objectives is ultimately determined by differences in outcomes, most papers solely focus on differences in policies. Given that there are no transitional dynamics in Model 1, limiting the discussion to the balanced growth path is not problematic. In Model 2, transitional dynamics arise, and welfare levels along the balanced growth path are not identical to lifetime utility. We discuss this issue in greater detail at the end of this section.

One of the few papers that considers outcomes is Monteiro and Turnovsky (2008) who develop a two-sector endogenous growth model with physical and human capital. The government provides one public service that enhances the production of final output and one public service that enhances the production of human capital. Both are derived from the flow of public expenditure. They present steady state growth rates and steady state welfare levels for several different combinations of the tax rate and public spending composition (under two alternative settings of the remaining model parameters). Whereas utility is derived from consumption, which in turn is derived from final output, the welfare benefits of spending on the production of human 
capital are less direct. They therefore find a significant trade-off between growth and welfare maximization. As noted above, this is likely to result in part from the dichotomous nature of the two public services.

The previous section has shown that it is difficult to draw specific conclusions from comparisons between the growth- and welfare-maximizing tax rates. As a result trade-offs in terms of fiscal policies are very difficult to predict if the precise model specification, and the specific values of key parameters, are unknown. To deal with this model and parameter uncertainty we numerically evaluate the growth rates and welfare levels along the balanced growth path for a large number of different values of the exogenous model parameters. By doing so some general conclusions about growth and welfare maximization can be derived even under model and parameter uncertainty and for a large array of situations and contexts.

\subsection{Methodology}

The procedure used consists of two steps: first, a large number of values for each exogenous model parameter were generated. No assumptions regarding the specific parameter values were made, but values were randomly drawn from two distributions. Both distributions are truncated so that each parameter is allowed to vary across some (plausible) range. The lower bound $(l)$ and the upper bound $(u)$ are chosen to reflect theoretical restrictions, econometric estimates and/or anecdotal evidence where available. The distributions assumed between the lower and upper bound include a Uniform distribution and a symmetric Normal distribution (with mean $\mu=\frac{(l+u)}{2}$, and standard deviation $\left.d=\frac{(u-l)}{1.96}\right)$.

Table 2 summarizes the parameter assumptions; each parameter set includes values for all exogenous parameters in Models 1 and 2. The parameter ranges are shown in Table 2. We generated 7728 parameter sets, based on 7728 independent draws for each distribution. ${ }^{15}$ Tables 3 and 4 show summary statistics for the simulated distributions resulting from the 7728

\footnotetext{
${ }^{15}$ The procedure was implemented in Maple. The programs are available upon request. We originally generated 10,000 different parameter sets. This number decreased to 7,728 when we truncated the range of parameters according to the lower and upper bounds.
} 
Table 2: Exogenous parameter ranges and distribution

\begin{tabular}{ccccc}
\hline & $l$ & $u$ & Distribution 1 & Distribution 2 \\
\hline$\sigma$ & 1.001 & 3 & Uniform & Normal \\
$\rho$ & 0.02 & 0.06 & Uniform & Normal \\
$\alpha$ & 0.1 & 0.45 & Uniform & Normal \\
$\beta$ & 0 & 0.6 & Uniform & Normal \\
$v$ & -1 & -0.001 & Uniform & Normal \\
\hline
\end{tabular}

Table 3: Normal parameter distribution

\begin{tabular}{lllll}
\hline & Mean & Std. Dev. & Min. & Max. \\
\hline$\sigma$ & 2.002 & 0.443 & 1.001 & 2.999 \\
$\rho$ & 0.04 & 0.009 & 0.02 & 0.06 \\
$\alpha$ & 0.273 & 0.078 & 0.1 & 0.45 \\
$\beta$ & 0.299 & 0.134 & 0 & 0.6 \\
$v$ & -0.499 & 0.224 & -1 & -0.001 \\
$\mathrm{~N}$ & \multicolumn{5}{c}{7728} \\
\hline
\end{tabular}

independent draws.

Secondly, the maximization procedures, and the resulting outcomes in both models, were solved numerically for the Uniformly and Normally distributed parameter values. The growth- and welfare-maximizing tax rates, $\tau^{*}$ and $\tau^{* *}$, were calculated as shown in the previous section. To compare both tax rates, the relative difference is calculated as:

$$
\left|\frac{\left(\tau^{* *}-\tau^{*}\right)}{\tau^{*}}\right| \times 100
$$

We then compare the growth rates and welfare levels that result from these

Table 4: Uniform parameter distribution

\begin{tabular}{lllll}
\hline & Mean & Std. Dev. & Min. & Max. \\
\hline$\sigma$ & 2.002 & 0.581 & 1.001 & 2.999 \\
$\rho$ & 0.04 & 0.012 & 0.02 & 0.06 \\
$\alpha$ & 0.273 & 0.101 & 0.1 & 0.45 \\
$\beta$ & 0.296 & 0.173 & 0 & 0.6 \\
$v$ & -0.501 & 0.287 & -1 & -0.001 \\
$\mathrm{~N}$ & \multicolumn{5}{c}{7728} \\
\hline
\end{tabular}


different growth- and welfare-maximizing fiscal policies. For Model 1, growth rates and welfare levels along the balanced growth path under growth maximization $\left(\gamma^{*}\right.$ and $\left.W^{*}\right)$ and welfare maximization $\left(\gamma^{* *}\right.$ and $\left.W^{* *}\right)$, are calculated. The level of welfare along the balanced growth path is calculated based on (14). Relative differences are similarly calculated as:

$$
\frac{\left(\gamma^{*}-\gamma^{* *}\right)}{\gamma^{*}} \times 100
$$

and

$$
\frac{\left(W^{* *}-W^{*}\right)}{W^{* *}} \times 100
$$

In Model 2, due to transitional dynamics, (14) is not identical to lifetime utility. That is, while the welfare-maximizing tax rate yields the highest possible lifetime utility, it does not necessarily represent the highest welfare levels along the balanced growth path. Owing to transitional dynamics, the computation of lifetime utility is highly complex in endogenous growth models with public finance and typically not performed so that we do not explicitly compare welfare under either growth or welfare maximization. However, we argue below that some conclusions can still be drawn. ${ }^{16}$

\subsection{Results}

Summary statistics for Model 1 are shown in Tables 5 and 6 . The tables show that, for both distributions, the mean and standard deviation of the relative difference between the growth- and welfare-maximizing tax rates are much larger than for the relative difference between the growth rate and welfare levels under growth and welfare maximization. The mean difference in tax rates is calculated at $14 \%$, while the mean difference in growth rates that result from these is less than $2.4 \%$ and the mean of the relative difference of welfare levels is less than $4.3 \%$. For the Normal distribution, differences are smaller than for the Uniform distribution, reflecting the lower probability of extreme values with the Normal distribution. The standard deviations (of

\footnotetext{
${ }^{16}$ There are papers that take a similar approach to tackle parameter uncertainty, albeit in different contexts (see for example Salhofer et al. (2001)).
} 
Table 5: Model 1 with Normal parameter distribution

\begin{tabular}{lllll}
\hline Variable & Mean & Std. Dev. & Min. & Max. \\
\hline$\tau^{*}$ & 0.475 & 0.111 & 0.12 & 0.738 \\
$\tau^{* *}$ & 0.505 & 0.096 & 0.179 & 0.752 \\
relative difference b/w tax rates & 10.412 & 13.044 & 0 & 195.055 \\
$\gamma^{*}$ & 0.104 & 0.054 & 0.01 & 0.423 \\
$\gamma^{* *}$ & 0.102 & 0.053 & 0.01 & 0.419 \\
relative difference b/w growth rates & 1.61 & 2.346 & 0 & 20.577 \\
relative difference b/w welfare & 2.544 & 4.982 & 0 & 77.562 \\
$\mathrm{~N}$ & & 7728 & & \\
\hline
\end{tabular}

relative differences) are also large in absolute terms for taxes but small for growth.

This is a key result: the trade-offs in terms of tax policies of the type found in previous sections exaggerate the trade-offs in terms of growth rate and welfare level outcomes. For example, the largest relative difference in tax rates generated from the different parameterizations is $195 \%$. This generates a difference in growth rates of just $16 \%$. Figures 5 and 6 plot the relative difference in tax rates against the relative difference in growth rates (Figure 5) and welfare levels (Figure 6) for all of the generated parameterization sets (based on the Normal distribution). While there is a positive correlation between the relative differences in tax rates and relative differences in outcomes in both figures, large differences in tax rates are associated with generally smaller differences in growth or welfare outcomes. Differences in the optimal tax rate are consistently associated with smaller differences in outcomes, especially in the case of growth rates (Figure 5).

Figures 7 and 8 shed more light on the distribution of the relative differences for the Normal distribution. They show that for more than $75 \%$ of the parameter sets that we generate, the relative differences between growth rates and welfare levels are generally below 5\%. This suggests that tradeoffs between growth and welfare maximization tend to be very small in most cases; hence maximizing growth and maximizing welfare yield roughly equivalent outcomes. The key conclusion from this exercise is that this result is not due to choices of particular parameter value combinations we might have 
Table 6: Model 1 with Uniform parameter distribution

\begin{tabular}{lllll}
\hline Variable & Mean & Std. Dev. & Min. & Max. \\
\hline$\tau^{*}$ & 0.466 & 0.143 & 0.105 & 0.749 \\
$\tau^{* *}$ & 0.499 & 0.126 & 0.125 & 0.772 \\
relative difference b/w tax rates & 14.181 & 20.984 & 0.001 & 261.516 \\
$\gamma^{*}$ & 0.114 & 0.076 & 0.007 & 0.583 \\
$\gamma^{* *}$ & 0.112 & 0.075 & 0.007 & 0.581 \\
relative difference b/w growth rates & 2.384 & 3.478 & 0 & 28.568 \\
relative difference b/w welfare & 4.268 & 9.559 & 0 & 185.425 \\
$\mathrm{~N}$ & & 7728 & & \\
\hline
\end{tabular}

chosen, but rather holds across a large number of alternative sets. The reason appears to be the relative 'flatness' of both the tax-growth curve and the tax-welfare curve between the growth- and welfare-maximizing tax rates. Hence, in this region fiscal policy is relatively ineffective. Since growth is essential for welfare, the tax rates typically do not differ to the extent that growth rates (and hence welfare) fundamentally differ under both objectives.

Tables 7 and 8 show equivalent summary statistics for Model 2. First, the tables show that, as in the case of Model 1, for both distributions the mean and the standard deviation of the relative difference between the growth- and welfare-maximizing tax rates are much larger than the equivalent relative differences in growth rates under growth and welfare maximization. Again, the assumed parameter distribution does not seem to matter. Figure 9, based on the Normal distribution, confirms that while there is a correlation between the relative differences in tax rates and relative differences in outcomes, the former tend to be much larger.

Secondly, Tables 7 and 8 also show that the mean relative difference in growth rates between growth and welfare maximization is below $9 \%$. Compared to the model with public services, this is noticeably larger. The reason is that with public capital there are transitional dynamics, with total welfare driven to a lesser extent by the growth rate along the balanced growth path. Therefore, growth- and welfare-maximizing tax rates, and hence growth rates, differ rather more with public capital. Figure 10 sheds more light on the distribution of the relative differences for the Normal distribution case. It shows 
Table 7: Model 2 with Normal parameter distribution

\begin{tabular}{lllll}
\hline Variable & Mean & Std. Dev. & Min. & Max. \\
\hline$\tau^{*}$ & 0.321 & 0.06 & 0.112 & 0.471 \\
$\tau^{* *}$ & 0.185 & 0.054 & 0.054 & 0.434 \\
relative difference b/w tax rates & 42.776 & 10.306 & 0.593 & 67.345 \\
$\gamma^{*}$ & 0.269 & 0.046 & 0.184 & 0.495 \\
$\gamma^{* *}$ & 0.246 & 0.052 & 0.148 & 0.494 \\
relative difference b/w growth rates & 8.840 & 4.542 & 0.001 & 25.614 \\
\hline number of observations when $W^{*}>W^{* *}$ & 7727 & & \\
\hline $\mathrm{N}$ & 7728 & & \\
\hline
\end{tabular}

Table 8: Model 2 with Uniform parameter distribution

\begin{tabular}{lllll}
\hline Variable & Mean & Std. Dev. & Min. & Max. \\
\hline$\tau^{*}$ & 0.318 & 0.08 & 0.104 & 0.493 \\
$\tau^{* *}$ & 0.19 & 0.073 & 0.039 & 0.501 \\
relative difference b/w tax rates & 41.121 & 13.767 & 0.02 & 67.882 \\
$\gamma^{*}$ & 0.278 & 0.064 & 0.185 & 0.618 \\
$\gamma^{* *}$ & 0.257 & 0.072 & 0.138 & 0.618 \\
relative difference b/w growth rates & 8.523 & 5.719 & 0 & 28.018 \\
\hline number of observations when $W^{*}>W^{* *}$ & 7727 & & \\
\hline $\mathrm{N}$ & 7728 & & \\
\hline
\end{tabular}


Figure 5: Relative differences of tax rates and growth rates in Model 1 (public services ; Normal distribution)

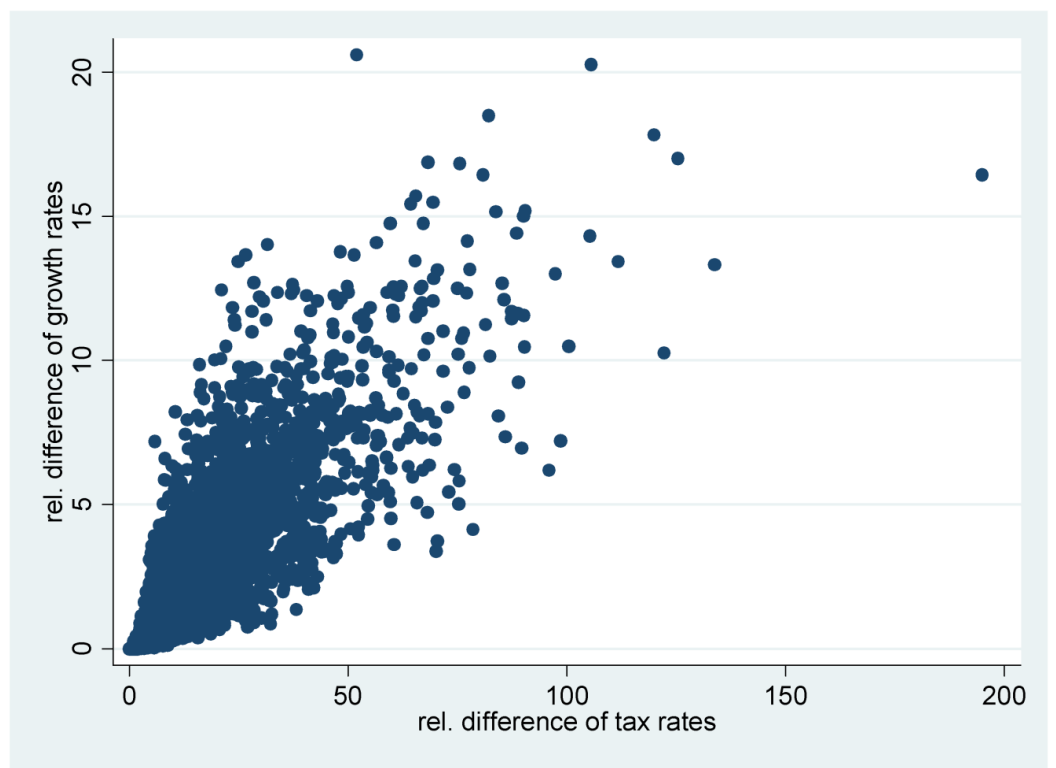

that for $75 \%$ of the parameter sets, the relative difference between growth rates is less than $12.5 \%$ (e.g. 3\% compared with $3.375 \%$ ), suggesting that growth rate trade-offs between growth and welfare maximization still tend to be moderate in most cases.

In common with most papers that develop endogenous growth models with public finance we do not compute lifetime utility where transitional dynamics occur, due to the complexity of the exercise in this case. While the standard approach in the literature to deal with transitional dynamics is to approximate them, the reliability of using linearized systems as an approximation to the true non-linear system is unclear and, as Atolia et al. (forthcoming) show, it may be problematic in some other contexts. This leaves some doubt regarding the relative welfare level differences in Model 2. Nevertheless, we believe that the difference in terms of lifetime utility between growth and welfare maximization would remain small were transitional dynamics to be considered.

Lifetime utility can be conceived as the sum of two components - the utility during the transitional period, and utility along the balanced growth 
Figure 6: Relative differences of tax rates and welfare levels in Model 1 (public services ; Normal distribution)

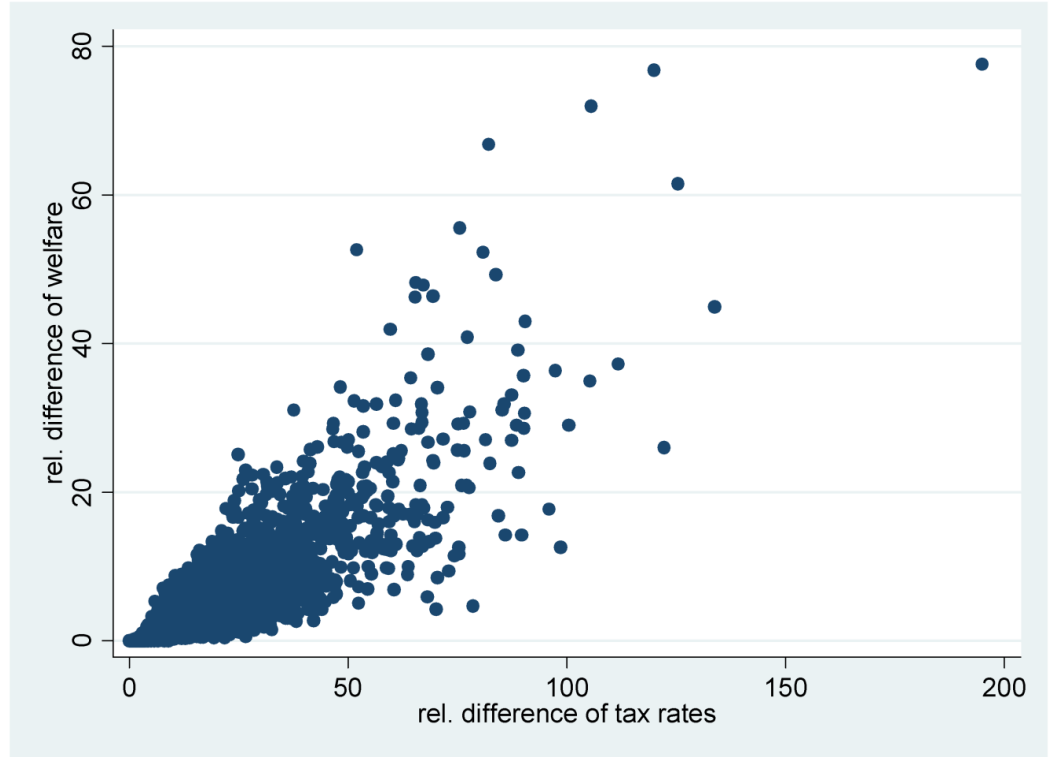

path. As shown in Tables 7 and 8, along the balanced growth path welfare is typically larger under growth maximization than under welfare maximization because the welfare-maximizing policy reflects transitional dynamics. This effect dampens the welfare-reducing effect of growth maximization. In addition and more importantly, the modest difference between the growth rate under growth and under welfare maximization are also likely to suggest that the impact of switching regimes from growth to welfare maximization on the economy, and therefore on lifetime utility, is small.

\section{Conclusions}

This paper has considered the difference between growth and welfare maximization by comparing income tax rates under both growth and welfare maximization in generalizations of two established models of endogenous growth with fiscal policy. It has also compared growth rates and welfare levels as outcomes of fiscal policy in these models. Several conclusions can be drawn from this exercise. 
Figure 7: Relative differences of growth rates in Model 1 (public services ; Normal distribution)

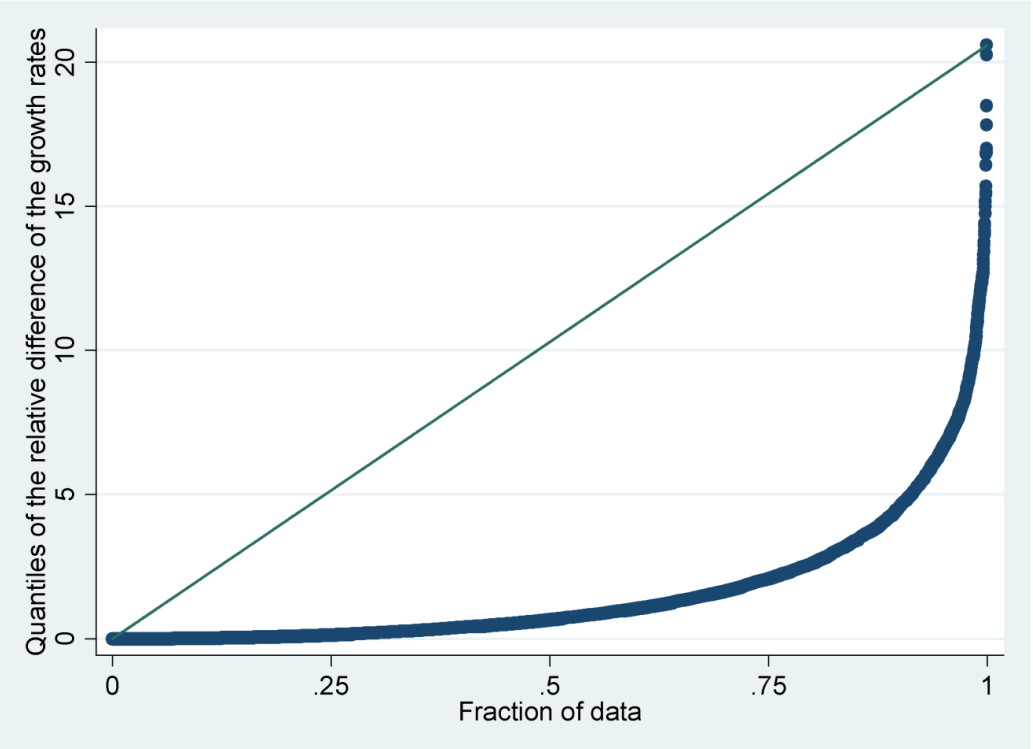

Firstly, comparisons between the growth- and welfare-maximizing tax rates across several different models show that the central results of the existing literature are not robust to small changes in their underlying assumptions. The results depend crucially on the way that fiscal policy is assumed to be effective. In particular, it was shown that even if public services or public capital enter the utility function, the relationship between the growth- and welfare-maximizing tax rates is ambiguous, and the two may even coincide. These comparisons show that for this class of endogenous growth models, without exact knowledge of the model parameters, differences between the growth- and welfare-maximizing fiscal policies are hard to predict.

The second conclusion modifies the policy concerns raised by the first. The relative differences between growth- and welfare-maximizing tax rates tend to be much larger than relative differences between growth rates for models with public services and public capital, and welfare levels for models with public services. It was shown that relative welfare and growth trade-offs in models with public services are very small, while in models with public capital, the growth (and most likely the welfare) trade-off is larger but still seems 
Figure 8: Relative differences of welfare in Model 1 (public services ; Normal distribution)

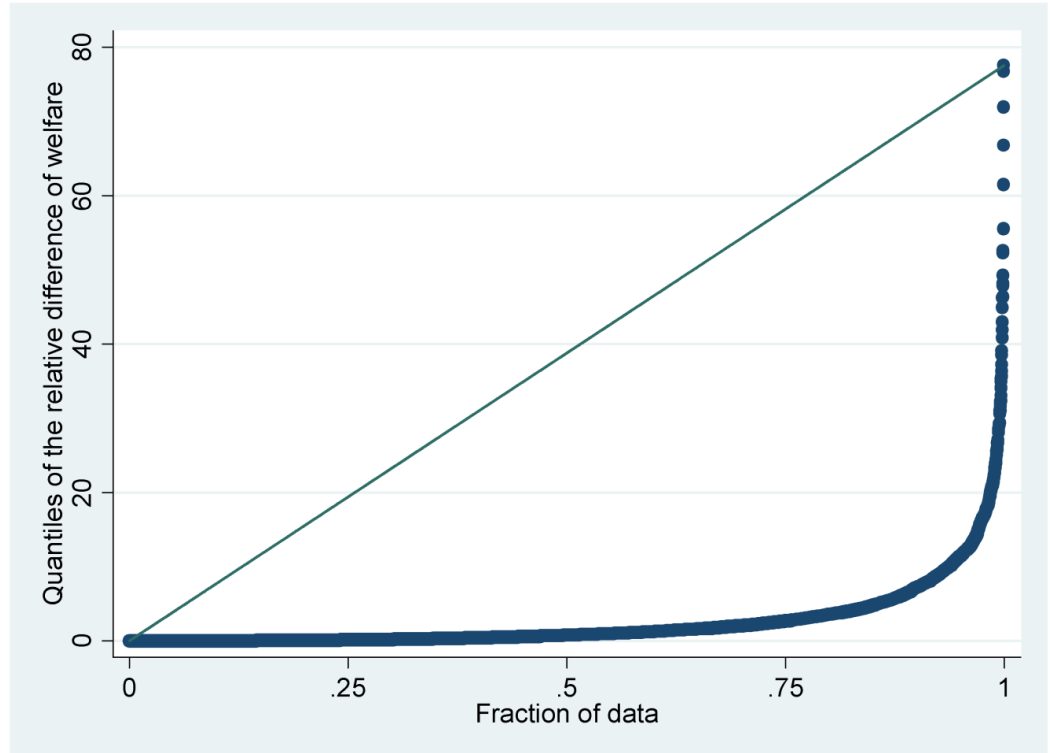

moderate. Parameter uncertainty was handled by assuming a distribution function of all parameters instead of adopting specific values. Conditional on the general class of models, this would appear to imply that the choice between growth and welfare maximization is unlikely to have large impacts on growth and, in the case of models with public services, on welfare levels.

The Barro and Futagami Models and their extensions form key reference points in policy discussions of the long-run growth effects of fiscal policy. Nevertheless, growth-maximizing and welfare-maximizing fiscal policies could be compared in a more general framework. While one option is to include the choice between labor and leisure explicitly, as for instance in Turnovsky (1999), rather than treating labor supply as exogenously fixed, this model extension seems unlikely to change our results qualitatively. The reason is that the growth-maximizing tax rate in our models is determined by the technology of production and by the nature of the productive effects of public spending. It is conceivable that the welfare-maximizing tax rate changes; however it can reasonably be expected that these changes are not large enough to significantly change our results because differences between 
Figure 9: Relative differences of tax rates and growth rates in Model 2 (public capital ; Normal distribution)

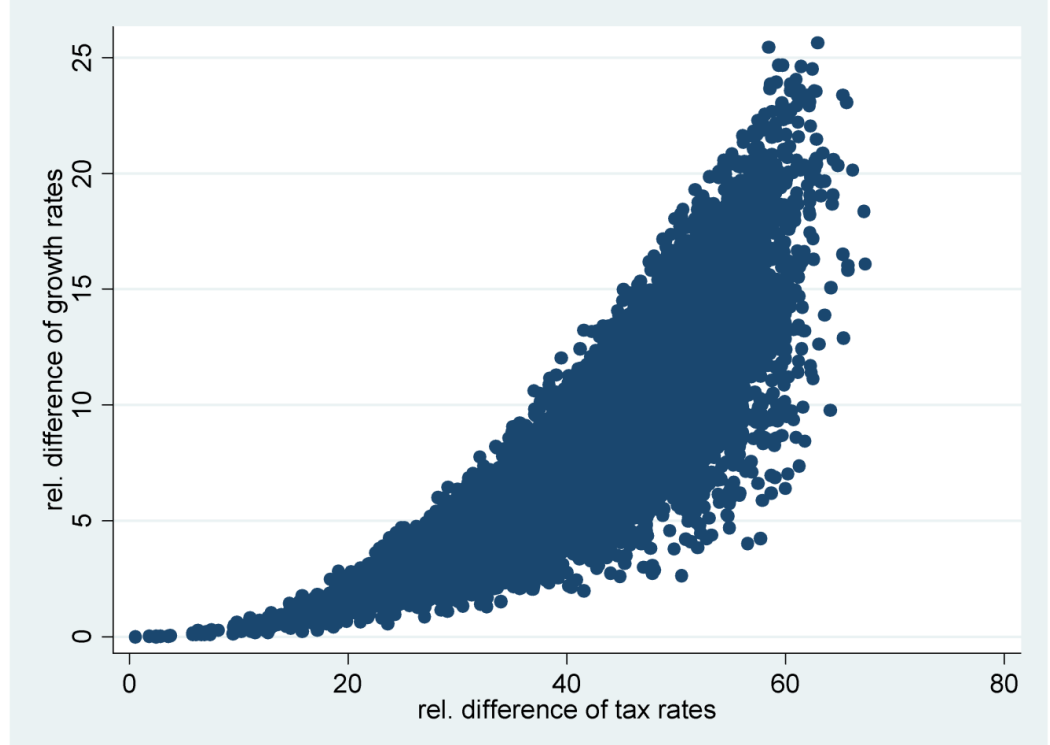

growth maximization and welfare maximization would continue to be driven by the factors that we identified in this paper. In addition, if utility is specified in a way that the utility-enhancing effects of public spending do not affect the marginal utility of consumption and leisure in relative terms, they leave the choice between labour and leisure unaffected suggesting that for simplicity, the labour supply of households can be considered as exogenously given.

A more interesting extension which future research could tackle, would be to consider a combination of Models 1 and 2 in which the government simultaneously provides public services and public capital and therefore also sets the shares of spending of public services and of public investment, which would introduce an additional fiscal policy instrument. ${ }^{17}$ This would allow comparisons of the growth- and welfare-maximizing composition of public spending, and also allow interactions between the level of taxation and the composition of public spending to be explored. For the Cobb-Douglas tech-

\footnotetext{
${ }^{17}$ Ghosh and Roy (2004) and Misch et al. (2011) have developed such models for example.
} 
Figure 10: Relative differences of growth rates in Model 2 (public capital ; Normal distribution)

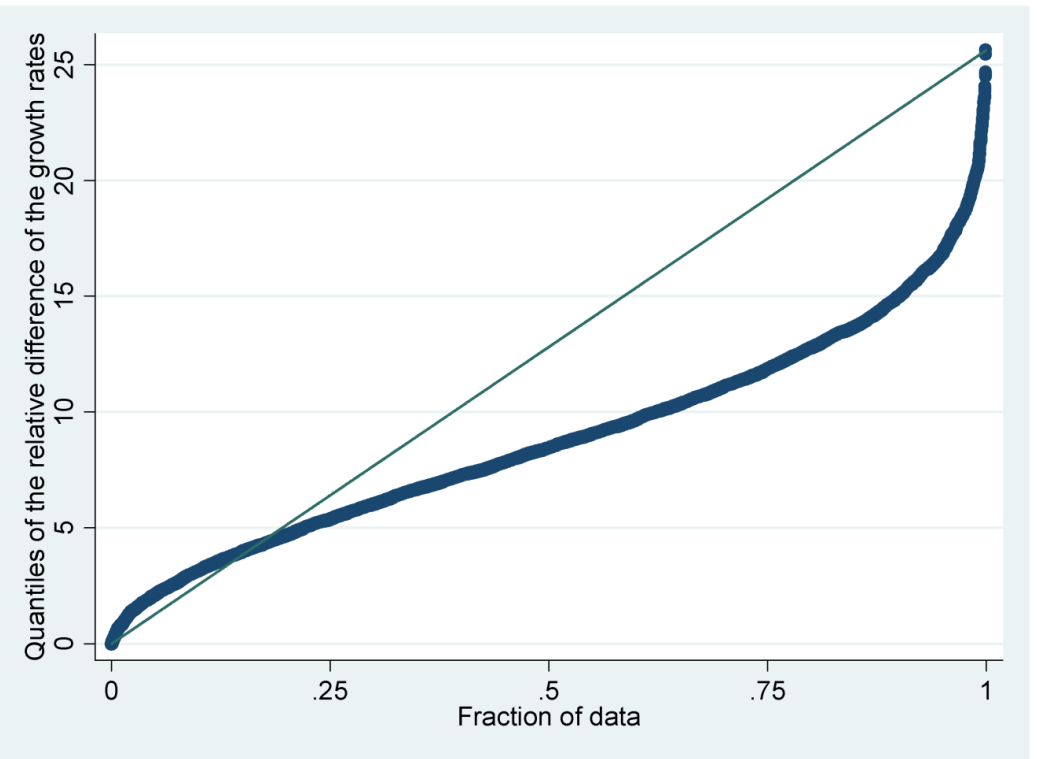

nology case, Ghosh and Roy (2004) show that the optimal tax rate and the optimal spending shares are interrelated (in the sense that the tax rate affects the optimal public spending composition and vice versa). Similarly, Misch et al. (2011) show that the optimal tax rate and the share of resources spent on public services are interrelated when public and private inputs to production are complements under growth maximization. These findings imply that in a model with public capital and public services, the relation between the growth- and welfare-maximizing fiscal policies would become more still more complex..$^{18}$

The results of this paper, though derived from relatively abstract models, have important policy implications. The knowledge available to governments

\footnotetext{
${ }^{18}$ To illustrate, Misch et al. (2011) demonstrate that in a second-best situation where the shares of public spending on public services and of public investment are not set at their growth-maximizing values, the growth-maximizing level of taxation is higher compared to a first-best situation. While the optimal tax rate and the optimal public spending composition are also interrelated under welfare maximization as shown by Ghosh and Roy (2004), it is unclear if second-best interactions under welfare maximization are similar to the case of growth maximization. Thus, conclusions regarding differences between growthand welfare maximizing tax rates may be affected by how the public spending shares are set and vice versa.
} 
is inevitably imperfect, such that they typically face informational constraints regarding household preferences and the magnitude of any utility-enhancing effects of public services. Further, because social welfare is harder to measure than output, governments are often tempted to treat output growth maximization as a proxy for maximizing welfare. The results of this paper suggest, however, that the implied welfare trade-offs between growth and welfare maximization may be small; we find many cases where the growthmaximizing fiscal policy yields roughly the same welfare outcome as the welfare-maximizing policy. If growth rates are indeed susceptible to fiscal policy, and if the growth-enhancing effect of public services, or public capital, are easier to measure, then benevolent governments might reasonably seek to maximize the growth rate instead as a second-best strategy. In addition, the results show that fiscal policy tends to be relatively ineffective in altering welfare levels and growth rates between the growth- and welfaremaximizing tax rates, at least in models with public services. Changes in fiscal policy within this interval can be expected to have only a small impact on the economy.

Finally, the 'representative household' nature of the models considered here are such that they are clearly not well suited to considering intratemporal but inter-household distributional aspects though this is clearly an important fiscal policy trade-off for many governments. Where some public spending impacts both on output growth and welfare of an individual household and affects the distribution of that output across households, capturing these trade-offs is likely to require a much more complex model of the relevant interactions and choices. ${ }^{19}$

\footnotetext{
${ }^{19}$ See, for example, Li and Sarte (2004) who extend a Barro-type model to consider the impacts of progressive income taxation and productive public spending in the presence of heterogeneous households.
} 


\section{A Appendix}

\section{A.1 The Welfare-Maximizing Tax Rate in Model 2}

The present-value Hamiltonian that corresponds to the maximization problem of the government together with the first-order conditions of the household yield

$$
1+\frac{\beta}{1-\beta} \frac{x}{z} \frac{1}{y_{k_{G}}}=(1-\tau) \frac{y_{k}}{y_{k_{G}}}
$$

with $x=c / k$ and $z=k_{G} / k$. This condition determines $\tau^{* *}$. The steady state values of $x$ and $z, \tilde{x}$ and $\tilde{z}$, can be derived from (A.2) and (A.3). Along the balanced growth path, $\frac{\dot{k}_{G}}{k_{G}}=\frac{\dot{c}}{c}$ holds which can be written as

$$
\tau \frac{y}{k_{G}}=\frac{1}{\sigma}\left((1-\tau) y_{k}-\rho\right)
$$

Likewise, from $\frac{\dot{k}}{k}=\frac{\dot{c}}{c}$,

$$
x=(1-\tau) \frac{y}{k}-\frac{1}{\sigma}\left((1-\tau) y_{k}\right)+\frac{\rho}{\sigma}
$$

\section{A.2 Growth- and Welfare-Maximizing Tax Rates in the Centralized Economy}

This appendix derives the optimal tax rates under growth and welfare maximization in the centralized economy. In contrast to the market economy considered above, the central planner takes into account the positive externality of private investment that arises because private investment increases output which in turn results in higher levels of public revenue and thereby higher levels of productive public services.

In Model 1, the growth- and welfare-maximizing tax rates are derived as follows. In (1), $g$ is substituted using (3). Solving for $y$ and deriving with respect to $k$ results in an expression of the social marginal returns of private investment. By using the resulting expression for $y_{k}$, one can obtain the growth- and welfare-maximizing tax rates in the centralized economy, $\tau_{c}^{*}$ and $\tau_{c}^{* *}$, in the same way as in the market economy.

Again using numerical examples where closed-forms are not available, our results show that with $v=0, \tau_{c}^{*}=\tau^{*}$ and $\tau_{c}^{* *}=\tau^{* *}$ even if $\beta>0$. However, 
once $v=-1$, there are significant differences between the centralized and the market economy. Our numerical examples suggest that the optimal tax rates are significantly below the equivalents on the market economy. For instance, in the case where $\beta=0.3$, and with the remaining model parameters set as in Figures 1 and 2, the growth-maximizing tax rate in the centralized economy equals $83 \%$ of that in the market economy, and the welfare-maximizing tax rate amounts to $96 \%$ of that in the centralized economy.

In Model 2, the growth-maximizing tax rate can be obtained by implicitly differentiating (11) where $y_{k}$ is the social marginal return to private capital. Under welfare-maximization, the government sets $c, k, \tau$ and $k_{G}$ in a way that maximizes welfare. Numerical examples with $\beta=0.3$ and with the remaining exogenous model parameters set as in Figures 3 and 4 suggest that the picture now slightly changes. Whereas with $v=0$ the growthmaximizing tax rates in the centralized and market economies continue to be identical $\left(\tau_{c}^{*}=\tau^{*}\right)$, the welfare-maximizing tax rate in the centralized economy, $\tau_{c}^{* *}$ amounts only to about $91 \%$ of its equivalent in the market economy. With $v=-1$, growth- and welfare-maximizing tax rates in the centralized and in the market economies differ. The growth-maximizing tax rate amounts to only $82 \%$ of the growth-maximizing tax rate in the market economy. By contrast, the welfare-maximizing tax rate in the centralized economy now exceeds that in the market economy: $\tau_{c}^{* *}=1.04 \tau^{* *}$. A more systematic comparison of the growth- and welfare-maximizing tax rates in the centralized economy is beyond the scope of this paper, but these examples suggest there may be merit in undertaking this exercise within our modeling framework as optimal tax rates appear to differ between the centralized and the market economies.

\section{References}

[1] P. Agénor, "Health and Infrastructure in a Model of Endogenous Growth", Journal of Macroeconomics, vol. 30, no. 4, pp. 1407-1422, 2008b. 
[2] P. Agénor, "Fiscal Policy and Endogenous Growth with Public Infrastructure", Oxford Economic Papers, vol. 60, no. 1, pp. 57-87, 2008a.

[3] P. Agénor and K. Neanidis, "The allocation of public expenditure and economic growth", Centre for Growth and Business Cycle Research, Economic Studies, University of Manchester, Discussion Paper Series, no. 069, 2006.

[4] M. Atolia, S Chatterjee, and S. Turnovsky, "How Misleading is Linearization? Evaluating the Dynamics of the Neoclassical Growth Model", Journal of Economic Dynamics and Control, forthcoming.

[5] S. Baier and G. Glomm, "Long-run growth and welfare effects of public policies with distortionary taxation", Journal of Economic Dynamics and Control, vol. 25, no. 12, pp. 2007-2042, 2001.

[6] R. Balducci, "Public expenditure and economic growth. A critical extension of Barro's (1990) model", Dipartimento di Economia, Università Politecnica delle Marche, Research Working Paper, no. 240, 2005.

[7] R. Barro, "Government Spending in a Simple Model of Endogenous Growth", Journal of Political Economy, vol. 98, no. 5, pp. 103-25, 1990.

[8] V. Chari, L. Christiano, and P. Kehoe, "Optimal fiscal policy in a business cycle model", Journal of Political Economy, vol. 102, no. 4, pp. 617-652, 1994.

[9] S. Chatterjee and S. Ghosh, "Public Goods, Congestion, and Fiscal Policy: Do Consumption-Based Instruments Matter?", Working Paper No. 09-07, 2009.

[10] S. Devarajan, V. Swaroop, and Z. Heng-fu, "The composition of public expenditure and economic growth", Journal of Monetary Economics, vol. 37, no. 2, pp. 313-344, 1996.

[11] K. Futagami, Y. Morita, and A. Shibata, "Dynamic Analysis of an Endogenous Growth Model with Public Capital", Scandinavian Journal of Economics, vol. 95, no. 4, pp. 607-625, 1993. 
[12] S. Ghosh, "On public investment, long-run growth, and the real exchange rate", Oxford Economic Papers, vol. 54, no. 1, pp. 72-90, 2002.

[13] S. Ghosh and A. Gregoriou, "The Composition of Government Spending and Growth: Is Current or Capital Spending Better?", Oxford Economic Papers, 2008.

[14] S. Ghosh and U. Roy, "Fiscal Policy, Long-Run Growth, and Welfare in a Stock-Flow Model of Public Goods", Canadian Journal of Economics, vol. 37, no. 3, pp. 742-756, 2004.

[15] A. Greiner and H. Hanusch, "Growth and Welfare Effects of Fiscal Policy in an Endogenous Growth Model with Public Investment", International Tax and Public Finance, vol. 5, no. 3, pp. 249-261, 1998.

[16] A. Greiner and T. Kuhn, "Growth Effects of Fiscal Policy in an Endogenous Growth Model with Productive Public Spending and Pollution". Center for Empirical Macroeconomics, Bielefeld University, Working Paper, vol. 37, 2001.

[17] IMF and World Bank, "Fiscal Policy for Growth and Development: Further Analysis and Lessons from Country Case Studies". Background Paper for Development Committee Spring 2007 Meetings, 2007.

[18] S. Lau, "Welfare-Maximizing vs. Growth-Maximizing Shares of Government Investment and Consumption", Economics Letters, vol. 47, no. 3, pp. 351-359, 1995.

[19] W. Li and P-D.Sarte, "Progressive Taxation and Long-run Growth", American Economic Review, vol. 94, no. 5, pp. 1705-1716, 2004.

[20] F. Misch, N. Gemmell, and R. Kneller, Fiscal Policy and Growth with Complementarities and Constraints on Government. ZEW Discussion Paper No. 11-018, 2011.

[21] G. Monteiro and S. Turnovsky, "The Composition of Productive Government Expenditure: Consequences for Growth and Welfare", Indian Growth and Development Review, vol. 1, no. 1, pp. 57-83, 2008. 
[22] I. Ott and S. Turnovsky, "Excludable and Non-Excludable Public Inputs: Consequences for Economic Growth", Economica, vol. 73, no.292, pp. 725-748, 2006.

[23] H. Park and A. Philippopoulos, "Dynamics of Taxes, Public Services and Endogenous Growth", Macroeconomic Dynamics, vol. 6, no. 02, pp. 187-201, 2002.

[24] K. Salhofer, E. Schmid, F. Schneider, and G. Streicher, "Empirical Policy Analysis with Parameter Uncertainty: The Case of Austrian Agricultural Policy," Unpublished manuscript. Available at http://www.econ.jku.at, 2001.

[25] W. Semmler, A. Greiner, B. Diallo, A. Rezai, and A. Rajaram, "Fiscal Policy, Public Expenditure Composition, and. Growth Theory and Empirics", World Bank Policy Research Paper, no. 4405, 2007.

[26] C. Tsoukis and N. Miller, "Public Services and Endogenous Growth", Journal of Policy Modeling, vol. 25, no. 3, pp. 297-307, 2003.

[27] S. Turnovsky, "Fiscal Policy, Adjustment Costs, and Endogenous Growth", Oxford Economic Papers, vol. 48, no. 3, pp. 361-381, 1996.

[28] S. Turnovsky, "Fiscal Policy in a Growing Economy with Public Capital", Macroeconomic Dynamics, vol. 1, no. 03, pp. 615-639, 1997.

[29] S. Turnovsky, "Fiscal Policy and Growth in a Small Open Economy with Elastic Labour Supply", Canadian Journal of Economics, pp. 11911214, 1999.

[30] S. Turnovsky, "The Transitional Dynamics of Fiscal Policy: Long-Run Capital Accumulation and Growth", Journal of Money, Credit, and Banking, vol. 36, pp. 883-910, 2004 